\title{
DOS NUEVAS ESPECIES DE IBATIA (APOCYNACEAE) DE ARGENTINA
}

\author{
Héctor A. Keller ${ }^{1,2}$ \\ ${ }^{1}$ Instituto de Botánica del Nordeste, IBONE-CONICET, Sargento Juan Bautista Cabral 2131, CC 209, 3400 Corrientes, \\ Corrientes, Argentina; kellerhector@hotmail.com (autor corresponsal). \\ ${ }_{2}^{2}$ Facultad de Ciencias Forestales, Universidad Nacional de Misiones, Bertoni 124 km 3, 3380 Eldorado, Misiones, Argentina.
}

\begin{abstract}
Keller, H. A. 2020. Two new species of Ibatia (Apocynaceae) from Argentina. Darwiniana, nueva serie 8(1): 328-336.

Two new species of Ibatia (Apocynaceae, Asclepiadoideae, Asclepiadae, Gonolobinae) from the Chaco region of the Salta province, Argentina, are described and illustrated: I. dummelii and I. micrantha. Ibatia dummelii was collected in the Chaco Serrano and is distinguished from related species by the reflex perianth; Ibatia micrantha was collected in the Dry Chaco and is characterized by the very small flowers. As a result, the number of species registered for Ibatia in the Argentinian Flora now rises to seven.
\end{abstract}

Keywords. Argentinian Flora; Asclepiadoideae; Gonolobinae; taxonomy.

Resumen. Keller, H. A. 2020. Dos nuevas especies de Ibatia (Apocynaceae) de Argentina. Darwiniana, nueva serie 8(1): 328-336.

Se describen e ilustran dos nuevas especies de Ibatia (Apocynaceae, Asclepiadoideae, Asclepiadae, Gonolobinae) a partir de ejemplares recolectados en la región chaqueña de la provincia de Salta: $I$. dummelii e I. micrantha. Ibatia dummelii fue recolectada en el Chaco Serrano y se distingue de especies afines por el perianto reflexo; Ibatia micrantha fue recolectada en el Chaco Seco y se caracteriza por sus flores muy pequeñas. Como resultado, se eleva a siete el número de especies de Ibatia registradas para la Flora Argentina.

Palabras clave. Asclepiadoideae; Flora Argentina; Gonolobinae; taxonomía.

\section{INTRODUCCIÓN}

Gonolobinae es una de las ocho subtribus de la tribu Asclepiadae de la subfamilia Asclepiadoideae (Apocynaceae) endémicas del nuevo mundo (Keller \& Liede-Schumann, 2017). Esta subtribu cuenta hasta el presente con 45 géneros distribuidos principalmente en regiones tropicales y subtropicales del continente americano (Endress et al., 2018).

El género Ibatia Decne. (Apocynaceae, Asclepiadoideae, Asclepiadae, Gonolobinae) comprende plantas volubles o erectas con pubescencia mixta, con láminas foliares hasta de $15 \mathrm{~cm}$ de largo, ovadas a suborbiculares de base cordada a subcordada; las inflorescencias son cortamente pedunculadas con pocas a muchas flores y con la corola rotácea a campanulada, blanca, verde o púrpura, los lóbulos miden de 3-6,5 mm de largo, son ovados a oblongos y la corona ginostegial es anular, cupuliforme o pentalobada y presenta los segmentos estaminales e interestaminales soldados; el ginostegio es estipitado; las anteras son radialmente prominentes con dehiscencia dorso-apical; las polinias son pendientes, usualmente obovadas, proximalmente hialinas; la cabeza estilar es cóncava o rostrada; y por último, presentan los folículos muricados (Endress et al., 2018). 
Desde su creación, Ibatia ha experimentado un devenir intrincado y la amplitud de atributos que lo definen se va dilatando a medida que más muestras se incorporan a estudios de filogenia molecular. El género fue propuesto sobre la base de características "únicas" de la corona estaminal (ciatiforme) y de la estructura estigmática (pentagonal con apículo bífido) de Ibatia maritima (Jacq.) Decne., especie tipo y por entonces única del género. A lo largo de más de siete décadas posteriores se fueron incorporando otros representantes mediante descripciones de nuevos taxones y nuevas combinaciones (Grisebach, 1864[1862], 1866; Karsten, 1865; Fournier, 1885; Herter, 1909), hasta que Woodson (1941), en un intento por simplificar la taxonomía de la entonces "familia Asclepiadaceae" propuso que este género, al igual que muchos otros de la actual subtribu Gonolobinae, fueran tratados como sinónimos de Matelea Aubl. La prevalencia de conceptos genéricos amplios dentro de la subtribu Gonolobinae, fue durante décadas bien recibida por la mayoría de los especialistas en la subfamilia, quienes nutrieron a los géneros Matelea y Gonolobus Michx. con cuantiosos taxones de morfología floral diversa. Sin embargo, estudios filogenéticos moleculares de la subtribu (Krings \& Saville, 2007; Krings et al., 2008; Morillo, 2015) permitieron dar cuenta del eclecticismo de la propuesta de Woodson (1941) y la necesaria resurrección de algunos géneros, incluyendo a Ibatia. Dicho taxón fue restablecido y redefinido por Morillo (2012) quien mediante nuevas combinaciones incluyó a varias especies de Matelea y Gonolobus, como representantes de Ibatia. Si bien en dicha contribución el autor desarrolla a modo de "enumeración de caracteres distintivos" una muy dilatada descripción del género, seguidamente reconoce una inconveniente variabilidad de los atributos señalados como diagnósticos por Decaisne (1844) para la especie tipo, es decir la morfología de la corona y el ginostegio. También señala la necesidad de desarrollar nuevos estudios filogenéticos para abordar el género, incorporando taxones, como Matelea calchaquina C. Ezcurra \& Belgrano y especies erectas de Pseudoibatia Malme, que presentan una morfología que no se ajusta a lo que Morillo (2012) denomina las "típicas Ibatias".

Desde su resurrección, Ibatia ha ampliado el número de taxones hasta alcanzar cerca de una treintena de especies que habitan en bosques o matorrales estacionalmente secos (Endress et al., 2018). En la
Argentina hasta el presente se reconocen cinco especies del género (Morillo, 2013; Zuloaga et al., 2019), tres descriptas originalmente como representantes del género Gonolobus (Schlechter, 1906; Malme, 1932; Meyer, 1944) y dos como Pseudoibatia (Schlechter, 1906; Malme, 1927, 1932). Sin embargo, resultados inéditos de estudios de filogenia molecular en elaboración (Liede et al. en prep.), permitirán incorporar otras especies para el país, hasta el presente comprendidas dentro del género Matelea. Asimismo, se han recolectado recientemente muestras para extracción de $\mathrm{ADN}$ de especies como M. calchaquina y M. australis (Malme) Pontiroli (=Pseudoibatia australis Malme), lo que eventualmente, como lo ha señalado Morillo (2012), permitirá tener un panorama más completo del género.

En la presente contribución, se describen e ilustran dos nuevas especies de género Ibatia: I. dummelii e I. micrantha, ambas presentan caracteres de la corona y el ginostegio que se ajustan al género Ibatia en su definición original y caracteres vegetativos $\mathrm{y}$ reproductivos que se ajustan a su definición ampliada, así como también, atributos que permiten diferenciarlas de las especies descriptas hasta el presente. Como resultado de estos dos nuevos taxones, el número de especies de Ibatia presentes en la Argentina asciende a siete, y por este motivo, se brinda también, una clave para diferenciar todas las especies presentes en la flora argentina.

\section{MATERIALES Y MÉTODOS}

Luego del análisis detallado de los ejemplares, se estudiaron muestras, imágenes y literatura de las especies del género, así como también de especies de géneros afines presentes en la Argentina y en países limítrofes próximos a las zonas de hallazgo, principalmente Gonolobus, Matelea y Pseudolachnostoma Morillo.

Para obtener las imágenes empleadas en el proceso del estudio del material y posteriormente confeccionar las ilustraciones correspondientes a las nuevas especies aquí descriptas, se utilizó una cámara fotográfica con alta resolución (Sonny, DSCHX400V) y un microscopio estereoscópico (Zeizz, Stemi DV4). El indumento de la planta y el polinario fueron examinados con microscopio óptico (Leica, DM500) con cámara fotográfica incorporada (ICC50). 
Para la extracción de los polinarios y el estudio de los caracteres reproductivos, las flores fueron ablandadas mediante su decocción, con lo cual las dimensiones descriptas corresponden al material rehidratado.

\section{TRATAMIENTO TAXONÓMICO}

Ibatia dummelii H. A. Keller, sp. nov. TIPO: Argentina, Salta, Capital, Cerro San Bernardo, $24^{\circ} 47^{\prime} 18,5^{\prime \prime} \mathrm{S} ; 65^{\circ} 23$ ' 43, 1" W, 04-III-2020, (fl), H. A. Keller, C. J. Dummel \& L. J. Ritter 14097 (holotipo CTES!; isotipo SI!). Figs. 1 y 2.

Related to Ibatia pucara Morillo but different by the calyx lobes ciliates and reflexed; corolla rotate with the tube shorter ( $2 \mathrm{~mm})$, the lobes longer (4-5 $\mathrm{mm})$ and completely reflexed; corona tube taller and thinner $(3,8-4 \times 2,8-5 \mathrm{~mm})$.

Voluble de ca. $8 \mathrm{~m}$ de alto, entrenudos de $7-20 \mathrm{~cm}$ de largo $\times 0,15-0,2 \mathrm{~cm}$ de diám, algo angulosos o aplanados, glabrescentes y suberosos cuando viejos, los jóvenes con pubescencia bifaria y con tricomas de 0,1-0,8 $\mathrm{mm}$, eglandulares, retrorsos, aciculares, multiseptados, amarillentos y con tricomas glandulares menores a $0,1 \mathrm{~mm}$, capitados, obscuros. Hojas opuestas; pecíolos de 3-4,6 cm de largo $\times$ 0,7-0,9 $\mathrm{mm}$ de diám., flexuosos, con pubescencia similar a la de los tallos jóvenes, pero los tricomas aciculares son antrorsos, de 0,1-0,5 mm; láminas foliares de 5,4-11,5 × 3,1-6 $\mathrm{cm}$, ovadas a oblongo-ovadas, de base cordada y ápice acuminado, membranáceas, con 5-8 pares de nervios secundarios arqueados, base del epifilo con 3-6 coléteres de 0,3-0,6 mm, blanquecinos, cónicos, ambas caras con pubescencia bifaria, similar a las de los pecíolos; los tricomas glandulares se observan como puntos negros a trasluz, margen densamente antrorso-ciliado. Inflorescencias 6-9-floras, con 2-4 flores en antesis simultáneas; pedúnculo de 1-3 mm de largo $\times 1$ 1-1,5 mm de diám., pubescente; brácteas de 1,5-2,8 $\times 0,3-0,6 \mathrm{~mm}$, estrechamente triangulares a lineares, pilosas; pedicelos de 3-6 $\mathrm{mm}$ de largo $\times$ 0,3-0,5 mm de diám., pubescentes; cáliz verde pálido, con el tubo de ca. 1,2 $\mathrm{mm}$ de largo. $\times 2 \mathrm{~mm}$ de diám., cara interna con 2-3 coléteres de 0,25$0,3 \times 0,15-0,2 \mathrm{~mm}$, triangulares bajo el seno, del lado interno, lóbulos de 5-6 × 2,5-3 mm, reflexos, retorcidos, angostamente ovados a elípticos, agudos, cara abaxial y margen con tricomas aciculares antrorsos; corola rotácea, con el tubo de ca. $2 \mathrm{~mm}$ de largo $\times 3 \mathrm{~mm}$ de diám., glabra, blanca-lilácea, lóbulos de 4-5 × 3-3,8 mm, anchamente ovados, emarginados, nervado-reticulados, reflexos y con márgenes recurvados en antesis, blanquecinos; corona de 3,8-4 mm de largo × 2,8-3 mm de diám. en la base, y de 4,9-5 $\mathrm{mm}$ de diám. en el ápice, obcónica-ciatiforme soldada basalmente al estípite del ginostegio y al tubo de la corola a $1,5 \mathrm{~mm}$ sobre la base del mismo, carnosa, negro-purpúrea, con 5 lóbulos apicales de ca. $0,5 \times 1,1 \mathrm{~mm}$, ligeramente bidentados, margen crenulado en los lóbulos y el seno; ginostegio de $3 \mathrm{~mm}$, oculto por la corona, estípite de 1,9-2,1 $\mathrm{mm}$ de base truncadamente cónica, de 0,5 mm, cabeza estilar de 1-1,1 mm, estrellado-pentagonal, borde convexo, parte media cóncava con un pequeño mamelón central, anteras subtriangulares, ligeramente inclinadas hacia el eje floral, la cara frontal de $1,2 \mathrm{~mm}$ de lat.; retináculo de $0,2 \times 0,22 \mathrm{~mm}$, sagitado, visiblemente exerto por sobre el borde de la cabeza estilar, polinias de $0,5 \times 0,35 \mathrm{~mm}$, asimétricamente obdacrioideas, oblicuamente colgantes, caudículas de ca. $0,3 \mathrm{~mm}$, articuladas, con expansión de ca. $0,25 \mathrm{~mm}$ de lat. en la inserción de las polinias; ovario de 3-3,2 mm de largo $\times 0,8-1 \mathrm{~mm}$ de diám., largamente aguzado en el ápice, superficie con protuberancias dispuestas en hileras. Fruto no visto, posiblemente muricado.

Etimología. Especie dedicada al Ing. Claudio Javier Dummel, profesor de Morfología y Sistemática Vegetal de la Universidad Nacional de Misiones (UNaM), quien halló la única población conocida de la especie.

Distribución y hábitat. Sólo conocida para el Cerro San Bernardo, situado en cercanías de la ciudad de Salta, Argentina. La vegetación predominante corresponde al Chaco Serrano. En el estrato superior predominan especies arbóreas como Handroanthus impetiginosus (Mart. ex DC.) Mattos (Bignoniaceae), Anadenanthera colubrina (Vell.) Brenan (Fabaceae), Ceiba speciosa (A. St.-Hil.) Ravenna (Malvaceae), el estrato intermedio se caracteriza por la presencia frecuente de Bougainvillea spinosa (Cav.) Heimerl (Nyctaginaceae) y Vasconcellea quercifolia A. St.Hil. (Caricaceae) (Delucchi, 1995). 


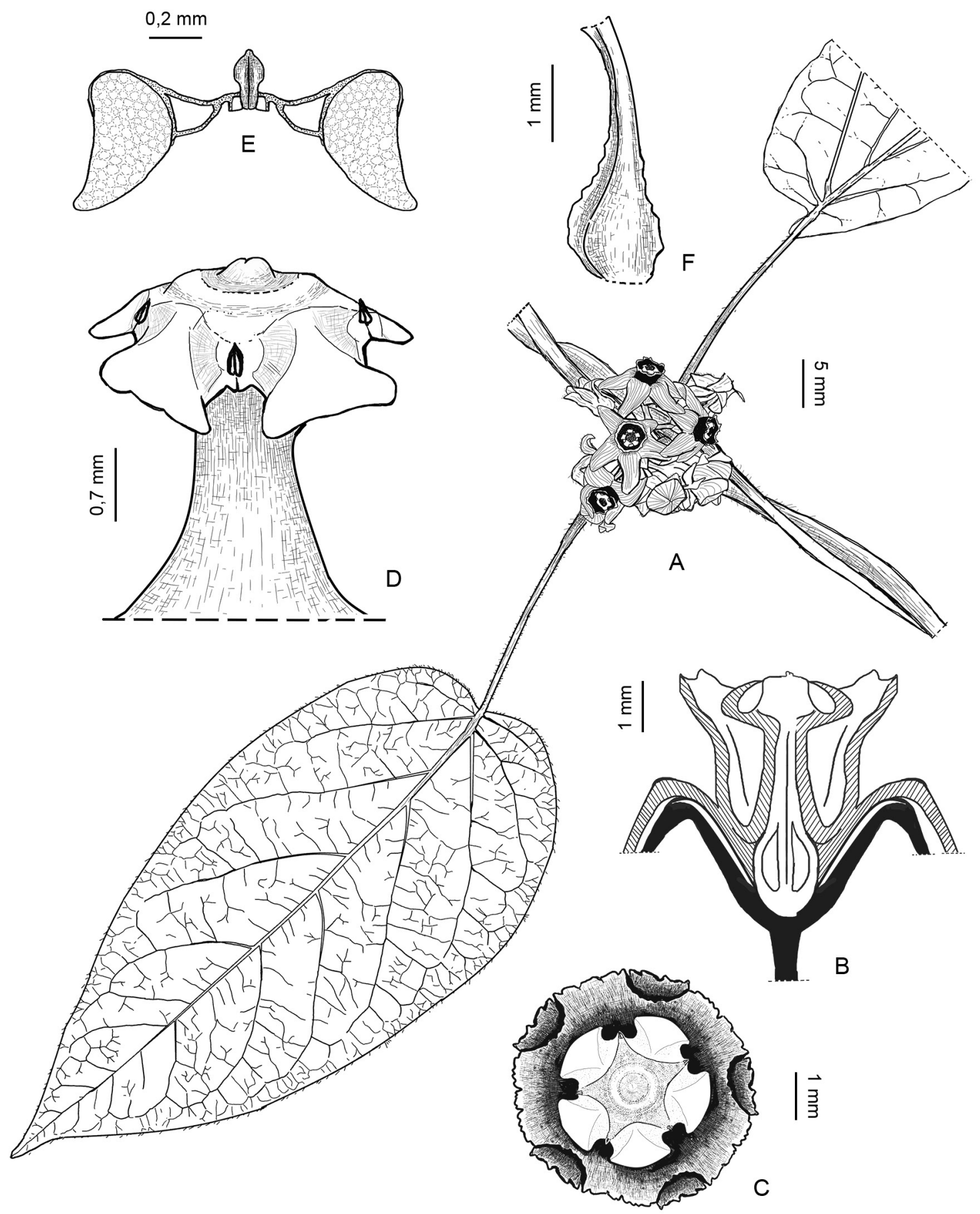

Fig. 1. Ibatia dummelii H. A. Keller. A, hoja e inflorescencia. B, corte longitudinal de la flor mostrando perianto reflexo, corona ginostegial, ginostegio y ovario. C, corona y cabeza ginostegial en vista superior. D, ginostegio. E, polinario. F, ovario. Dibujos del autor (holotipo). 

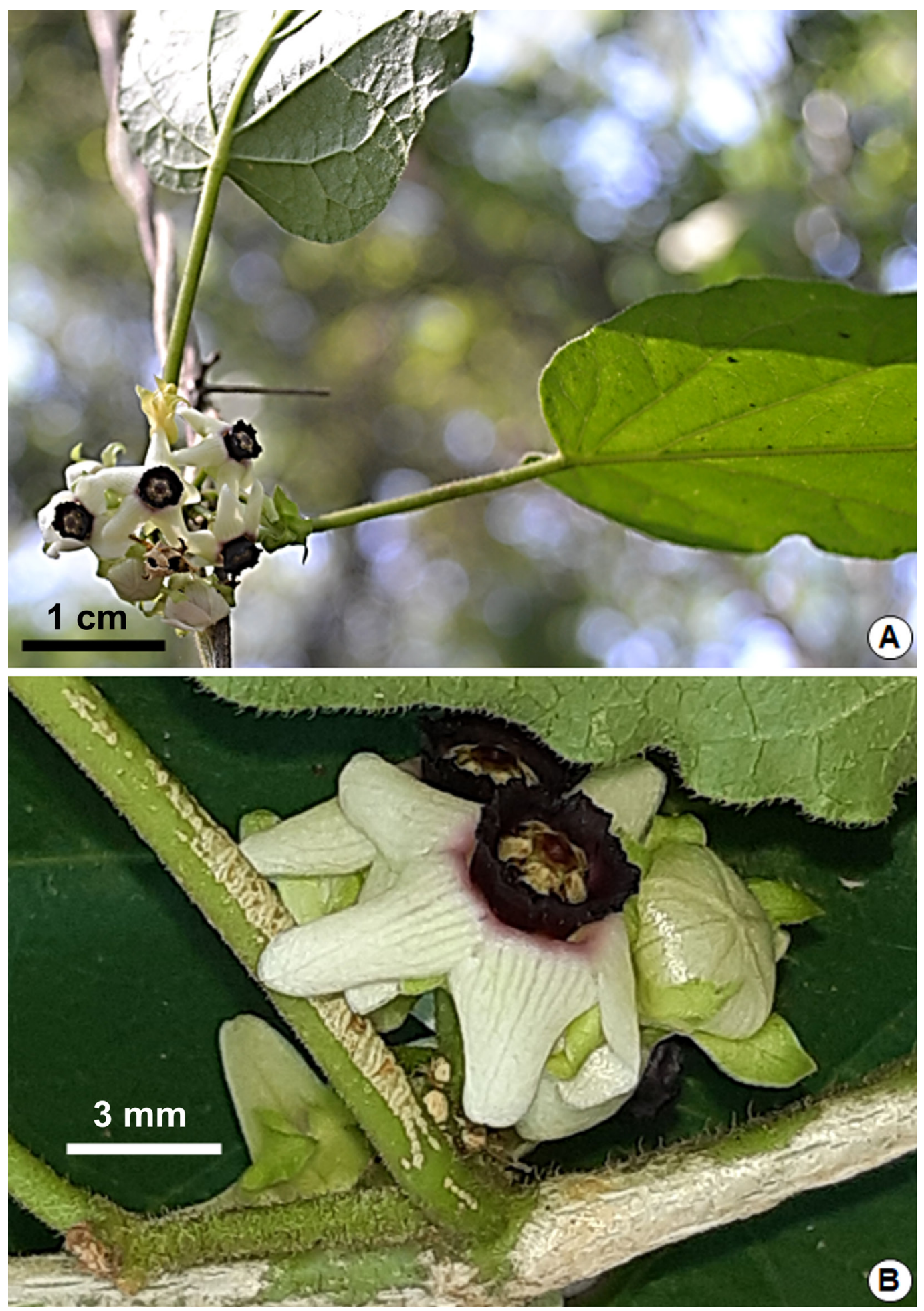

Fig. 2. Ibatia dummelii H. A. Keller. A, rama florífera. B, flor. Fotos: Claudio Dummel. Figura en color en la versión en línea http://www.ojs.darwin.edu.ar/index.php/darwiniana/article/view/886/1181 
Observaciones. El cáliz y la corola con piezas fuertemente reflexas y la corona en forma de copa alta que sobrepasa en altura al ginostegio, son caracteres que recuerdan a Pseudolachnostoma. Éste es un género recientemente establecido, sin estudios de filogenia molecular, que cuenta con una docena de especies distribuidas desde América Central hasta el centro oeste de Sudamérica (Morillo, 2012). El representante más austral, P. reflexum (Hemsl.) Morillo, llega hasta La Paz (Bolivia) a más de 1000 $\mathrm{km}$ al norte de Salta. Dichos caracteres florales fueron usados en una clave para distinguir este género afín de Ibatia (Morillo, 2016). Sin embargo, el ejemplar procedente del Cerro San Bernardo exhibe diversos atributos frecuentes en Ibatia, entre los que se destacan la presencia de hojas con base cordada, los lóbulos del cáliz en relación con los de la corola son relativamente largos (1/2 o más largos), los lóbulos de la corola anchamente ovados, las polinias asimétricamente obdacrioideas y la pubescencia mixta con tricomas eglandulares largos y tricomas capitados cortos en los órganos vegetativos. Las especies de Pseudolachnostoma tienen hojas con base obtusa o redondeada y presentan los lóbulos del cáliz muy cortos en relación con los de la corola ( $1 / 3$ o menos), los que por lo general son oblongos. Por otro lado, sus polinias son siempre largamente piriformes y en la descripción del género sólo se mencionan tricomas eglandulares en la superficie del mismo.

Dentro del género Ibatia y el complejo Matelea s.l., los taxones Ibatia pucara Morillo, de Santa Cruz, Bolivia, I. sartago-diaboli (Goyder) Morillo, de Cochabamba, Bolivia y Matelea calchaquina C. Ezcurra \& Belgrano, de Salta, Argentina, presentan, al igual que I. dummelii, la corola con colores pálidos y el ginostegio largamente estipitado (Ezcurra \& Belgrano, 2007; Goyder, 2008; Morillo, 2012). Las dos últimas especies se diferencian fácilmente de I. dummelii por presentar la corona con 5 lóbulos libres entre sí. Por su parte, Ibatia pucara, que también florece en marzo, comparte varios atributos vegetativos y florales con I. dummelii, como el hábito voluble, el tamaño de las hojas, los lóbulos del cáliz más largos que los de la corola, y la corona tubular-ciatiforme que supera en altura al ginostegio, por lo que se trata de una especie muy afín a la que aquí se describe. Sin embargo, I. dummelii presenta el perianto con los lóbulos totalmente reflexos luego de la antesis, mientras que en I. pucara son reflexos sólo apicalmente; los lóbulos del cáliz son ciliados en la primera y eciliados en la segunda, y además, la corola es rotácea con el tubo de hasta $2 \mathrm{~mm}$ de largo y con los lóbulos de 4-5 mm de largo en la primera, y en la segunda es campanulada, con el tubo de 2,52,7 mm de largo y con los lóbulos de 3,5-4 mm de largo. La corona de I. dummelii es más esbelta, de 3,8-4 mm de largo y hasta $5 \mathrm{~mm}$ de diám. en la parte más ancha, mientras que en I. pucara mide de 3-3,2 $\mathrm{mm}$ de largo y 5,5-5,8 $\mathrm{mm}$ de diám.

La zona en donde se colectó el material típico de I. dummelii, es un área protegida destinada a la recreación, y no se dispone de información sobre la población hallada ni evidencias sobre otras poblaciones, por lo que no se cuentan con datos suficientes para evaluar su estado de conservación.

Esta especie ha sido hallada en flor en marzo y posiblemente fructifique en abril-mayo.

Ibatia micrantha H. A. Keller, sp. nov. TIPO: Argentina. Salta, Rivadavia, Ruta 81, $21 \mathrm{~km} \mathrm{SE}$ de Coronel Juan Solá (Morillos), 10-XII-1979 (fl, fr), A. Schinini 19577 (holotipo CTES-98256!). Fig. 3.

Differs from all known species of the genus by its very small flowers with the calyx lobes $1,6-2 \times$ $0,8-1 \mathrm{~mm}$ and corolla lobes $2-2,2 \times 1,1-1,3 \mathrm{~mm}$.

Sufrútice erecto, de ca. $50 \mathrm{~cm}$ de alto, tallos de ca. $7 \mathrm{~mm}$ de diám. en la base y ramificados por encima de la misma; entrenudos de $1-3 \mathrm{~cm}$; corteza y ramas suberosas, rámulos hirsutos con pubescencia mixta formada por tricomas de 0,5-1,7 mm, eglandulares, multiseptados, y numerosísimos tricomas capitado-glandulares menores a $0,1 \mathrm{~mm}$, con una pubescencia similar en las hojas e inflorescencias. Hojas opuestas, decusadas: pecíolos de 0,4-3,7 cm de largo $\times 1$ 1-1,2 mm de diám; ; láminas de hojas basales de 1,3-4,7 × 1-3,5 cm ovadas a anchamente ovadas, de base cordada o redondeada y de ápice agudo a acuminado, las que acompañan a las flores de 1-2 × 0,3-1,5 $\mathrm{cm}$, elípticas, de base aguda a cuneada y de ápice agudo, epifilo con 4-7 coléteres cónicos blancos en la base, de ca $0,5 \mathrm{~mm}$ de largo $\times 0,2 \mathrm{~mm}$ de diám. Inflorescencias umbeliformes extra-axilares, distribuidas a lo largo de la porción 

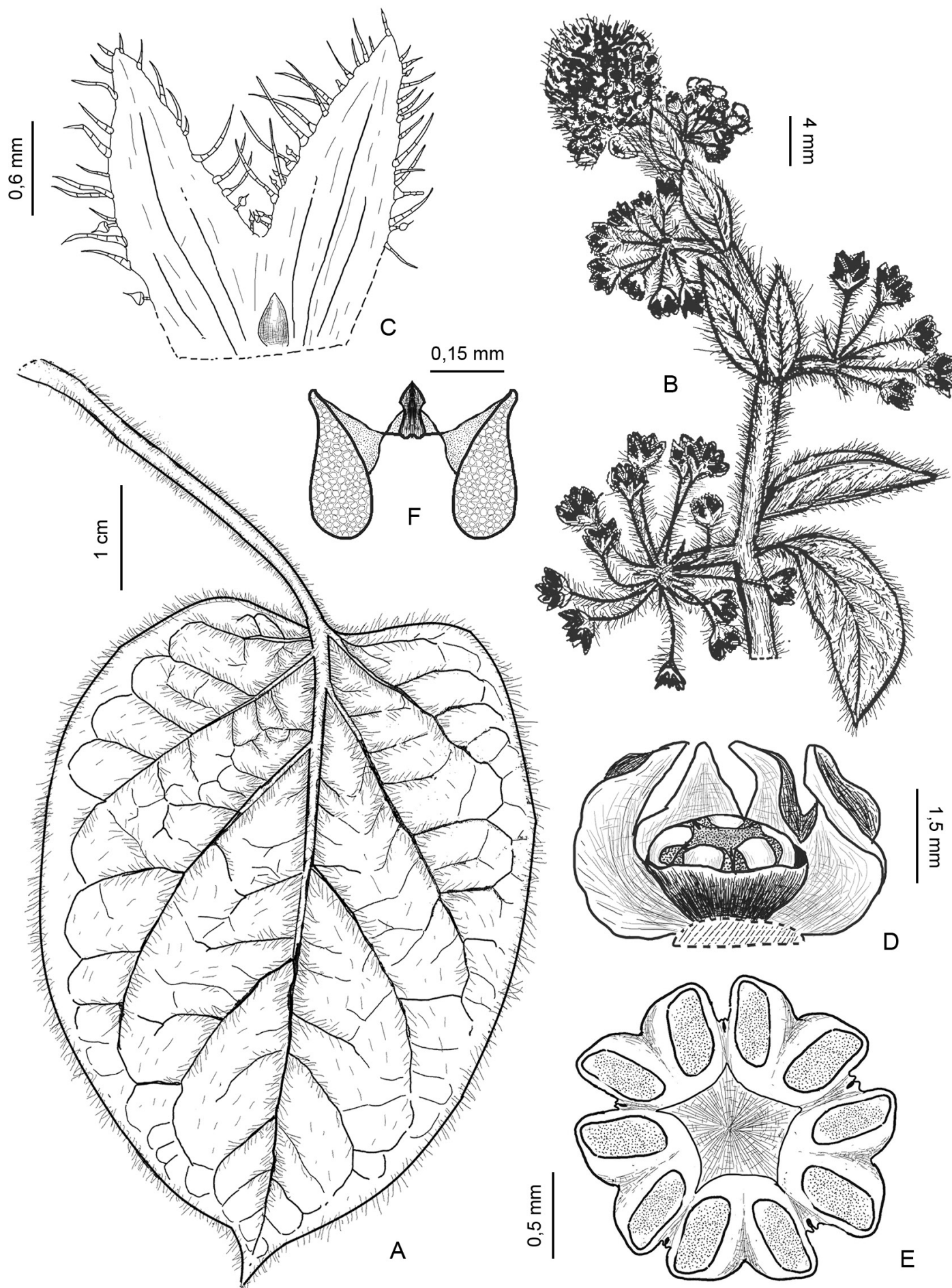

Fig. 3. Ibatia micrantha $\mathrm{H}$. A. Keller. A, hoja basal. B, rama florífera. C, lóbulos del cáliz con coléter en el seno. D, corola con un lóbulo extraído, mostrando la corona. E, cabeza del ginostegio y anteras en vista superior. F, polinario. Dibujos del autor (holotipo). 
apical de las ramas, pedúnculo de 3-7 $\mathrm{mm}$ de largo $\times 0,7-1 \mathrm{~mm}$ de diám., brácteas lineares hirsutas, con pubescencia bifaria de 1-2,1 $\times 0,1-0,22 \mathrm{~mm}$. Flores 8-13 por inflorescencia, pedicelos de 3-8 mm de largo $\times$ 0,2-0,3 $\mathrm{mm}$ de diám., hirsutos; cáliz campanulado, con tubo de ca. $1 \mathrm{~mm}$ de largo $\times$ $1,2 \mathrm{~mm}$ de diám., con 1 coléter cónico de ca. $0,3 \mathrm{~mm}$ de largo $\times 0,1 \mathrm{~mm}$ de diám. debajo de cada seno, del lado interno, lóbulos de 1,6-2 × 0,8-1 mm, triangulares, hirsutos en la cara dorsal, glabros en la cara ventral, corola rotácea, atropurpúrea, con el tubo de 1,1-1,2 mm de largo $\times 1,7-1,8 \mathrm{~mm}$ de diám., lóbulos de 2-2,2 × 1,1-1,3 mm, elípticos, pilosos en la cara abaxial, y glabros en la cara adaxial, de borde ciliado, ondulado; corona de 0,8-0,9 mm de largo $\times 2-2,1 \mathrm{~mm}$ de diám., anular, cupuliforme, entera, de borde ondulado; ginostegio de 1,2-1,3 mm de largo $\times 1,9-2 \mathrm{~mm}$ de diám, cortamente estipitado, pentalobulado; anteras de 0,7-0,8 × 0,6$0,7 \mathrm{~mm}$, dorsalmente convexas; retináculo de 0,12 $\times 0,05 \mathrm{~mm}$, sagitado, caudículas de ca. $0,2 \mathrm{~mm}$, sigmoideas, estrechadas cerca de la inserción con el retináculo, con expansiones laminares de ca. $0,1 \mathrm{~mm}$ de lat. en la inserción de las polinias y de ca. 0,03 $\mathrm{mm}$ de lat. en la inserción del retináculo, polinias de ca. $0,3 \times 0,2 \mathrm{~mm}$, asimétricamente dacrioideas, con el ápice recurvo. Fruto folículos (inmaduros) fusiformes, hirsutos, con máculas obscuras (primordios de acúleos).

Etimología. El epíteto específico hace referencia al tamaño de las flores, significativamente más pequeñas que las de las demás especies del género.
Distribución y hábitat. Conocida sólopor el ejemplar tipo recolectado en un bosque con predominancia de Schinopsis lorentzii (Griseb.) Engl. (Anacardiaceae) en la región semiárida del Chaco salteño.

Observaciones. La especie descripta presenta similitudes con Ibatia boliviensis (Schltr.) Morillo, como el hábito erecto y la morfología anular de la corona. Sin embargo, en I. boliviensis las inflorescencias son sésiles y los lóbulos de la corola son adaxialmente pilosos y miden ca. 6 $\mathrm{mm}$ de largo, mientras que en Ibatia micrantha las inflorescencias son pedunculadas y los lóbulos de la corola son adaxialmente glabros y no superan los 2,2 $\mathrm{mm}$ de largo. Otra especie que presenta afinidades con la que aquí se describe es Matelea foetida (Griseb.) C. Ezcurra \& Belgrano [=Pseudibatia foetida (Griseb.) Malme], una especie voluble que también presenta la corola adaxialmente glabra y corona anular, pero además del hábito trepador dicha especie tiene los lóbulos de la corola más grandes, de $5 \times 3,5 \mathrm{~mm}$, e inflorescencias sésiles.

Es posible que la especie aquí descripta se haya extinguido o al menos haya desaparecido la población de donde se coleccionó el material tipo, ya que fue colectada en el año 1979 y no se volvieron a encontrar ejemplares durante dos campañas posteriores llevadas a cabo en la localidad precisa señalada en la etiqueta del holotipo.

Esta especie se encontró con botones, flores y frutos inmaduros en diciembre, posiblemente florezca desde noviembre hasta enero y fructifique en enero-marzo.

\section{Clave de las especies de Ibatia presentes en la Argentina}

1. Corona cupuliforme 2

1. Corona con 5 lóbulos definidos, libres o apenas unidos en la base …............................................................. 5 2(1). Plantas erectas de menos de $1 \mathrm{~m}$ de alto. Perianto patente. Corona igualando en longitud o menor que el ginostegio .. 3 2. Plantas volubles de más de $5 \mathrm{~m}$ de alto. Perianto reflexo. Corona de mayor longitud que el ginostegio ................ 4 3(2). Inflorescencias pedunculadas. Lóbulos de la corola glabros en la cara adaxial .............. I. micrantha H.A. Keller

3. Inflorescencias sésiles. Lóbulos de la corola pilosos en la cara adaxial I. boliviensis (Schltr.) Morillo

4(2). Lóbulos de la corola glabros en la cara adaxial I. dummelii H.A. Keller

4. Lóbulos de la corola pilosos en la cara adaxial I. fiebrigii (Schltr.) Morillo

5(1). Lóbulos de la corona triangulares I. schreiteri (T. Mey.) Morillo

5 . Lóbulos de la corona flabeliformes o bífidos .. 6

6(5). Lóbulos de la corona flabeliformes I. venturii (Malme) Morillo

6. Lóbulos de la corona bífidos I. friesii (Malme) Morillo 


\section{AGRADECIMIENTOS}

Se agradece a Gelina Piezsko y Massimiliano Dematteis (CTES) por su asistencia con el herbario. A Claudio Dummel de la Facultad de Ciencias Forestales (UNaM) por su colaboración en la colección del material de herbario de I. dummelii. Por último, se agradece a dos revisores anónimos y editores que contribuyeron a mejorar sustancialmente el manuscrito.

\section{BIBLIOGRAFÍA}

Decaisne, J. 1844. Ibatia, en A. de Candolle (ed.), Prodromus Systematis Naturalis Regni Vegetabilis 8: 599, Paris: Treutel et Würtz.

Delucchi, G. 1995. Panorama Fitogeográfico del Noroeste Argentino. Museo 5: 63-67.

Endress, M.; Meve, U., Middleton, D. J. \& S. Liede-Schumann. 2018. Apocynaceae, in J. W. Kadereit \& V. Bittrich (eds), Flowering plants. Eudicots. Apiales and Gentianales (except Rubiaceae). Families and genera of vascular plants 15: 207-411. Springer, Cham.

Ezcurra, C. \& M. J. Belgrano. 2007. A new species and a new combination in Matelea (Apocynaceae, Asclepiadoideae) from Southern South America. Systematic Botany 32: 856861.

Fournier, E. 1885. Ibatia, en C. F. P. von Martius \& A. W. Eichler (eds.), Flora Brasiliensis. 6(4): 308-310. Munich. F. Fleischer.

Goyder D. 2008. Matelea sartago-diaboli, a new species of Apocynaceae: Asclepiadoideae from the inter-Andean valleys of Bolivia. Kew Bulletin 63: 335-338.

Grisebach, A. H. R. 1864 [1862]. Ibatia, en Flora of the British West Indian Islands: 421. London, Lovell Reeve \& Co.

Grisebach, A. H. R. 1866. Asclepiadeae, en Catalogus Plantarum Cubensium: 177-178. Leipzig: Engelmann.

Herter, W. 1909. Ibatia arechavalatae Herter nov. spec. Asclepiadacearum. Allgemeine Botanische Zeitschrift für Systematik, Floristik, Pflanzengeographie 15: 129.
Karsten, H. 1865. Ibatia, en P. Pinto (ed.), Flora de Colombia: 113-114, Santa Fé de Bogotá. Universidad Nacional de Colombia.

Keller H. A. \& S. Liede-Schumann. 2017. "The end of an enigma", a new subtribe and nomenclatural novelties in Asclepiadeae (Apocynaceae: Asclepiadoideae). Bonplandia 26 (2): 133-136.

Krings, A.; D. T. Thomas \& Q. Xiang. 2008. On the Generic Circumscription of Gonolobus (Apocynaceae, Asclepiadoideae): Evidence from Molecules and Morphology. Systematic Botany 33: 403-415.

Krings, A. \& A. C. Saville. 2007. Two new species and three lectotypifications in the Ibatia-Matelea complex (Apocynaceae: Asclepiadoideae) from northern South America. Systematic Botany 32: 862-871.

Malme, G. O. A. 1927. Asclepiadaceae mattogrossenses. Arkiv för Botanik. 21A (12): 1-27.

Malme, G. O. A. 1932. Asclepiadaceae autroamericanae praecipue andinae. Arkiv för Botanik 25A: 1-26.

Meyer, T. 1944. Asclepiadaceae, en H.R. Descole (ed.), Genera et species plantarum argentinarum 2: 1-273.

Morillo, G. 2012. Aportes al conocimiento de las Gonolobinae (Apocynaceae, Asclepiadoideae). Pittieria 36: 13-57.

Morillo, G. 2013. Aportes al conocimiento de las Gonolobinae II (Apocynaceae, Asclepiadoideae). Pittieria 37: 115-154.

Morillo, G. 2015. Aportes al conocimiento de las Gonolobinae Parte III (Apocynaceae, Asclepiadoideae). Pittieria 39: 191258.

Morillo, G. 2016. Nuevas especies y nuevas combinaciones en las Gonolobinae (Apocynaceae, Asclepiadoideae, Asclepiadeae) de Centro y Sudamérica. Lilloa 53(1): 89-106.

Schlechter, F. R. R. 1906. Plantae nova andinae imprimis Weberbauerianae II. Botanische Jahrbücher für Systematik, Pflanzengeschichte und Pflanzengeographie 37: 623.

Woodson, R. 1941. The North American Asclepiadaceae. I. Perspectives of the genera. Annals of the Missouri Botanical Garden 28: 193-244.

Zuloaga, F. O.; M. J. Belgrano \& C. A. Zanotti. 2019. Actualización del Catálogo de las Plantas Vasculares del Cono Sur. Darwiniana, nueva serie 7(2): 208-278. 